\title{
Markers of iron status are associated with stage of pregnancy and acute-phase response, but not with parity among pregnant women in Guinea-Bissau
}

\author{
Pernille Kæestel $^{1,2 *}$, Peter Aaby ${ }^{2,3}$, Christian Ritz ${ }^{1}$ and Henrik Friis ${ }^{1}$ \\ ${ }^{1}$ Department of Nutrition, Exercise and Sports, University of Copenhagen, Rolighedsvej 30, 1958 Frederiksberg C, Denmark \\ ${ }^{2}$ Bandim Health Project, INDEPTH Network, Apartado 861, Bissau, Guinea-Bissau \\ ${ }^{3}$ Research Center for Vitamins and Vaccines (CVIVA), Bandim Health Project, Statens Serum Institut, Artillerivej 5 , \\ 2300 Copenhagen S, Denmark
}

(Submitted 25 November 2014 - Final revision received 21 April 2015-Accepted 11 May 2015 - First published online 19 August 2015)

\begin{abstract}
While prenatal Fe supplementation prevents maternal Fe deficiency and anaemia, it is uncertain whether it improves infant health outcomes, at least when taken by Fe-replete women. Inflammation as well as physiological changes complicates the assessment of Fe status during pregnancy. In the present study, we measured the concentrations of serum ferritin and soluble transferrin receptors (sTfR), $\mathrm{Hb}$ and the acute-phase proteins C-reactive protein (CRP) and $\alpha_{1}$-antichymotrypsin (ACT) in a cross-sectional study among 738 pregnant women attending antenatal care in Guinea-Bissau, West Africa. Multiple linear regression analysis was used to identify the predictors of Fe status markers. The mean gestational age was 23 (SD 7) weeks. Serum ferritin values were lower with progressing gestation, from $27 \%$ lower during weeks 16-20 of gestation up to $59 \%$ lower after 29 weeks of gestation compared with early pregnancy. Using cutoff values for Fe deficiency as established in non-pregnant individuals, $52 \%$ of the women had sTfR levels $>2.3 \mathrm{mg} / \mathrm{l}$, while only $25 \%$ had serum ferritin levels $<12 \mu \mathrm{g} / \mathrm{l}$. Serum ferritin but also sTfR levels were elevated at increased serum CRP and ACT levels. The proportion of sTfR $>2.3 \mathrm{mg} / \mathrm{l}$ decreased to $47 \%$ after adjustment for elevated serum CRP and ACT levels. On the contrary, the proportion of serum ferritin $<12 \mu \mathrm{g} / \mathrm{l}$ increased to $33 \%$ after adjustment for ACT and CRP. The high proportion of elevated serum sTfR calls for pregnancy-specific cutoffs since increased erythropoiesis is expected in response to increased plasma volume of pregnancy. The present study further underlines the need to adjust for inflammation when serum sTfR and serum ferritin are used to assess Fe status in pregnancy.
\end{abstract}

Key words: Pregnancy: Iron status: Anaemia: Acute-phase responses: Ferritin: Transferrin receptors: Guinea-Bissau

Fe deficiency and anaemia in pregnant women is associated with preterm delivery and low birth weight of the offspring ${ }^{(1)}$ and with an increased risk of maternal mortality ${ }^{(2)}$. Antenatal Fe supplementation programmes are implemented worldwide to prevent maternal anaemia. However, the evidence for the beneficial effects of mass supplementation strategies on infant outcomes is limited ${ }^{(3)}$. A meta-analysis of studies on Fe supplementation in pregnancy has concluded that while $\mathrm{Fe}$ supplementation is efficacious in increasing maternal $\mathrm{Hb}$, the effects on infant health outcomes are inconclusive ${ }^{(4)}$. A more recent meta-analysis has suggested that prenatal $\mathrm{Fe}$ supplementation does improve birth weight, but with significant heterogeneity ${ }^{(5)}$. In general, while Fe supplementation may be an effective strategy to improve health outcomes among Fe-deficient individuals, it may not be beneficial among Fe-replete individuals. Fe also serves as a nutrient for pathogens, and Fe supplementation may aggravate morbidity in areas with a high burden of infections. Routine Fe supplementation has been associated with increased morbidity particularly in Fe-replete preschool children in a malaria endemic area $^{(6)}$. Therefore, it is crucial to be able to distinguish between Fe-deficient and Fe-replete individuals to assess the differential effects of interventions and to target interventions to Fe-deficient individuals. However, the interpretation of $\mathrm{Fe}$ status may be compromised during pregnancy due to altered nutrient metabolism and physiology, and potentially also to the acute-phase response to pregnancy and infections. Thus, there is a need for a better understanding of the factors associated with Fe status and the markers used to assess it.

Serum ferritin and serum soluble transferrin receptors (sTfR) are good indicators of Fe status in normal healthy individuals; however, due to haemodilution, increased erythropoiesis and

Abbreviations: ACT, $\alpha_{1}$-antichymotrypsin; CRP, C-reactive protein; expB, back-transformed exponentiated terms; sTfR, soluble transferrin receptors. 
other physiological changes during pregnancy, the conventional cut-off values to define Fe status may not be applicable to pregnant women. In addition, both markers are affected by the acute-phase response to inflammation ${ }^{(7-9)}$ including pregnancy $^{(10)}$. The acute-phase response involves cytokinestimulated production of acute-phase proteins, some of which initiate, others amplify and sustain, and others resolve the inflammatory response ${ }^{(11)}$. Therefore, it is recommended to adjust for different acute-phase proteins in an attempt to mitigate the misinterpretation of the markers of nutritional status that are involved in the acute-phase response ${ }^{(12)}$. The interpretation of the markers of nutritional status is therefore complicated in pregnant women, particularly in populations with a high burden of infectious diseases. Recently, the NIH project 'Inflammation and Nutritional Science for Programs/ Policies and Interpretation of Research Evidence' (INSPIRE) highlighted that although the association between inflammation and markers of Fe status is acknowledged, our knowledge on how best to account for it while assessing Fe status is limited ${ }^{(13)}$

We assessed Fe status in a cross-sectional study of 738 pregnant women attending antenatal care in Guinea-Bissau, West Africa. We have previously reported the associations between serum retinol and stage of pregnancy as well as the acute-phase response ${ }^{(14)}$. In the present study, we report serum concentrations of ferritin and sTfR adjusting for two acute-phase proteins.

\section{Participants and methods}

The present cross-sectional study was based on baseline data from a larger prenatal multi-micronutrient supplementation trial conducted in Guinea-Bissau, West Africa ${ }^{(15)}$. The study area was located in the capital of Guinea-Bissau where demographic surveillance has been carried out by the Bandim Health Project since 1978. Transmission of malaria (Plasmodium falciparum) was high and occurred throughout the year, although less severe in the dry season. The prevalence of HIV-1 infection was low, estimated at about 2-3\% when the study was carried out ${ }^{(16)}$. The staple food was rice, usually consumed with a small amount of fresh fish. Meat (beef, pork, goat or chicken) was more expensive and was less common. Around $25 \%$ in the larger study reported not to have consumed either fish or meat on the day before they were interviewed. Climate was tropical with one rainy season from June to November. Women were recruited at their first antenatal care visit from the Bandim Health Center from mid-May 2001 to mid-February 2002. During this period, a total of 842 women were recruited from the Bandim Health Center, of which 738 (87.6\%) volunteered to provide a venous blood sample. Information on age, gestational age and anthropometry was collected by two research nurses. Gestational age was based on the recall of the first day in the last menstrual period, and reported as quintiles in the analyses. Body weight was measured to the nearest $0 \cdot 1 \mathrm{~kg}$ (UNICEF Electronic Scale 890; Seca Limited) with the women barefooted wearing light clothing. Height was measured to the nearest $0 \cdot 1 \mathrm{~cm}$ using a metallic measuring tape. Obstetric history was merged with our data from a concomitant survey targeting all women of childbearing age in the study area conducted by the Bandim Health Project. Unfortunately, these data were only available for 574 (78\%) of the women. The main reason for incompleteness was most probably that we included women who were not permanent inhabitants of the study area, but only stayed until they gave birth, after which they returned home. The routine surveillance system did not include these individuals.

\section{Blood sampling and storage}

Peripheral blood was obtained by finger prick and $\mathrm{Hb}$ determined immediately. Venous blood was collected in the morning when women arrived at the health centre for antenatal care. A volume of $10 \mathrm{ml}$ blood was drawn after venepuncture using evacuated dry tubes (BD Vacutainers ${ }^{\circledR}$; Becton Dickinson). After coagulation at room temperature, the tubes were brought to the laboratory where serum was separated by centrifugation, and frozen at $-20^{\circ} \mathrm{C}$. Serum was stored for a maximum of 6 months at $-20^{\circ} \mathrm{C}$ and shipped frozen to the University of Copenhagen, Denmark where it was stored for a maximum of 12 months at $-80^{\circ} \mathrm{C}$ until analysis.

\section{Laboratory analyses}

$\mathrm{Hb}$ concentration was determined in peripheral blood using the HemoCue ${ }^{\circledR}$ system (B-Hemoglobin; HemoCue). Accuracy was approved by a weekly routine analysis of high-, normaland low-level calibrators $\left(\mathrm{HemoTrol}^{\circledR} ;\right.$ HemoCue). Serum ferritin (ferritin) was measured using an ELISA kit (DELFIA ${ }^{\circledR}$ Ferritin; Wallac). The detection limit was $0.5 \mu \mathrm{g} / \mathrm{l}$, and the inter-run variation was $5 \mathrm{CV} \%$. Depleted Fe stores were defined as ferritin levels $<12 \mu \mathrm{g} / \mathrm{l}^{(17)}$. Serum sTfR were measured using a commercial immunoassay (IDeA ${ }^{\circledR}$ STfR IT, catalogue no. 67968; Orion Diagnostica) using Cobas Mira Plus (Roche Diagnostics). The detection limit was $0.1 \mathrm{mg} / \mathrm{l}$, and the inter-run variation was $8 \mathrm{CV} \%$. Values above $2.3 \mathrm{mg} /$ 1 were considered to indicate tissue Fe deficiency according to the kit manual (IDeA ${ }^{\circledR}$ sTfR IT, catalogue no. 67968; Orion Diagnostica). Serum C-reactive protein (CRP) concentration reflecting acute inflammation was measured by a commercial test kit (catalogue no. A11A00175; ABX Diagnostics) using turbidimetry (Cobas Mira Plus; Roche Diagnostics). The detection limit was $3 \mathrm{mg} / \mathrm{l}$, and the inter-run variation was $3 \mathrm{CV} \%$. Values $\leq 3 \mathrm{mg} / \mathrm{l}$ were considered normal, and elevated concentrations were categorised as $>3-10,>10-$ 20 , and $>20 \mathrm{mg} / \mathrm{l}$. Serum $\alpha_{1}$-antichymotrypsin (ACT), which is part of the late acute-phase response while CRP is only elevated in the early response ${ }^{(18)}$, was quantified with rabbit anti-human ACT (DAKO) using turbidimetry (Cobas Mira Plus; Roche Diagnostics). The detection limit was $0.05 \mathrm{~g} / \mathrm{l}$, and the inter-run variation was $3 \mathrm{CV} \%$. Values $<0.3 \mathrm{~g} / 1$ were considered normal, and elevated concentrations categorised as $0.3-<0.4,0.4-<0.5,0.5-<0.6$ and $\geq 0.6 \mathrm{~g} / 1$ based on previous studies ${ }^{(19)}$. Malaria parasitaemia was assessed from Giemsa-stained thin and thick blood smears. Malarial parasites were identified by microscopic examination by a trained 
technician, and expressed as parasites per 200 leucocytes. In the absence of leucocyte count, malaria parasitaemia is reported as absent or present.

\section{Statistical analyses}

All statistical analyses were carried out using Stata/IC 12.1 (StataCorp LP). Serum ferritin and serum sTfR were logarithm-transformed $\left(\log _{\mathrm{e}}\right)$ to ensure symmetric distribution. We used simple and multiple linear regression analyses to investigate the relationship between predictors and the outcomes ferritin and sTfR. Gestational age, age, parity, serum CRP and serum ACT were included as predictors. Season, prior use of nutritional supplements and maternal height were further included in all models to adjust for potential confounding. Residual and normal probability plots were used to inspect normal distribution and homogeneity of residuals. Regression coefficients are reported as back-transformed exponentiated terms (expB). Values of expB above 1 indicate a positive association, while values below 1 indicate a negative association; an expB of 1.25 corresponds to a $25 \%$ increase in the outcome per unit change in the predictor considered. Missing values for parity (22\%) were considered missing at random and imputed through multiple imputation where an ordered multinomial model with malaria parasitaemia, serum retinol, serum $\beta$-carotene, serum $\alpha$-carotene, serum cholesterol, weight, triceps skinfold, subscapular skinfold, hip circumference, arm circumference, age and serum ACT as the predictors of parity was used to generate 100 imputed values of parity. The resulting 100 complete datasets were used for inference through the use of Rubin's rules. $P$ values $<0.05$ were considered significant. Adjusted values of serum ferritin and sTfR ( $\log _{e}(\mathrm{Fe}$ status indicator)) were generated from linear regression models of $\log _{\mathrm{e}}$ (indicator) with CRP (four categories) and ACT (five categories) as the only explanatory variables. Equations reflecting twenty combinations $(4 \times 5$ categories $)$ of the inflammatory response were generated. Adjusted values were converted to the original unit by back-transformation (exp(adjusted value)). A similar, but simpler adjustment method with four categories, based on elevated concentrations, was also applied. The categories were (1) neither CRP nor ACT, (2) CRP alone, (3) CRP and ACT, or (4) ACT alone. We used CRP levels $>3 \mathrm{mg} / \mathrm{l}$ and ACT levels $\geq 0.3 \mathrm{mg} / \mathrm{l}$ as the cut-off values.

\section{Ethical considerations}

After having received information about the study, women who were willing to participate gave their verbal consent. Since illiteracy was common in the study population, we did not use written consent. However, written information about the study was attached to the antenatal cards of participating women. Women identified with severe anaemia (defined as $\mathrm{Hb}$ level $<70 \mathrm{~g} / \mathrm{l}^{(20)}$ ) were given additional Fe supplements (daily $65 \mathrm{mg} \mathrm{Fe}$ as $\mathrm{FeSO}_{4}+250 \mu \mathrm{g}$ folic acid until delivery). All women were provided a free impregnated bed net and offered weekly malaria prophylaxis (chloroquine phosphate) until delivery. The study was approved by the National Ethical Board of the Ministry of Health, Guinea-Bissau, and by the Danish National Committee on Biomedical Research Ethics.

\section{Results}

The mean age of the 738 women was 23.9 years, one-third of the women were primigravid and another third were pregnant for the fourth time or more as reported previously ${ }^{(14)}$. Educational level was low, with $33 \%$ having no formal education. Prior use of nutritional supplements was reported by 132 (18\%) of the women, and the proportion increased by increasing gestational age at inclusion. Fe supplements were by far the most common, reported by 110 women. Hb, Fe status and inflammatory markers are summarised in Table 1 . Based on the unadjusted values, $58 \%$ had anaemia ( $\mathrm{Hb}$ level $<110 \mathrm{~g} / \mathrm{l}$ ), whereas $25 \%$ had depleted Fe stores (serum ferritin level $<12 \mu \mathrm{g} / \mathrm{l}$ ) and $52 \%$ had tissue Fe deficiency (serum sTfR level $>2.3 \mathrm{mg} / \mathrm{l})$. Elevated serum sTfR levels $(>2.3 \mathrm{mg} / \mathrm{l})$ were

Table 1. $\mathrm{Hb}$, markers of iron status and inflammation, and malaria parasitaemia in 738 pregnant women at enrolment

(Number of women and percentages; median and interquartile ranges)

\begin{tabular}{|c|c|c|c|c|}
\hline & $n$ & $\%$ & Median & Interquartile range \\
\hline Height $(\mathrm{cm})$ & 733 & & 160 & $156-165$ \\
\hline Malaria parasitaemia & 420 & 57.5 & & \\
\hline $\mathrm{Hb}(\mathrm{g} / \mathrm{l})$ & 696 & & 108 & $97-116$ \\
\hline$<110 \mathrm{~g} / \mathrm{l}$ & 406 & $58 \cdot 3$ & & \\
\hline Serum ferritin $(\mu \mathrm{g} / \mathrm{l})$ & 734 & & 23 & $12-49$ \\
\hline Soluble transferrin receptor $(\mathrm{mg} / \mathrm{l})$ & 732 & & $2 \cdot 3$ & $2 \cdot 0-3 \cdot 1$ \\
\hline C-reactive protein (mg/l) & 733 & & $3 \cdot 2$ & $3 \cdot 0-9 \cdot 2$ \\
\hline$\leq 3$ & 355 & $48 \cdot 4$ & & \\
\hline$>3-10$ & 214 & $29 \cdot 2$ & & \\
\hline$>10-20$ & 71 & $9 \cdot 7$ & & \\
\hline$>20$ & 93 & $12 \cdot 7$ & & \\
\hline$\alpha_{1}$-Antichymotrypsin $(\mathrm{g} / \mathrm{l})$ & 733 & & 0.3 & $0.3-0.4$ \\
\hline$<0.3$ & 247 & 33.7 & & \\
\hline $0.3-<0.4$ & 344 & $46 \cdot 9$ & & \\
\hline $0.4-<0.5$ & 89 & $12 \cdot 1$ & & \\
\hline $0.5-<0.6$ & 26 & 3.6 & & \\
\hline$\geq 0.6$ & 27 & 3.7 & & \\
\hline
\end{tabular}


not restricted to individuals with depleted Fe stores as $46 \%$ of those with serum ferritin levels between 12 and $150 \mu \mathrm{g} / \mathrm{l}$ had sTfR levels $>2.3 \mathrm{~g} / \mathrm{l}$ (data not shown). Fe-deficiency anaemia based on all the three indicators was observed in $12 \%$ ( $n$ 84/689) of the women. As for the acute-phase reactants, $52 \%$ had elevated serum CRP levels $(>3 \mathrm{mg} / \mathrm{l})$ and $66 \%$ had elevated serum ACT $(\geq 0 \cdot 3 \mathrm{~g} / \mathrm{l})$.

Although serum CRP level was higher in women who were included between 20 and 28 weeks of gestation compared with those recruited in early pregnancy, women who were recruited in late pregnancy ( $>28.6$ weeks) did not have elevated serum CRP levels (Table 2). In contrast, serum ACT was not associated with gestational age at any stage. Serum ACT as well as serum CRP concentrations were lower with increasing parity ( $P$ for linear trend $<0.03$ ), but the association between the acute-phase reactants and gestational age did not depend on parity (test for primiparity $\times$ gestational age interaction $P>0 \cdot 3$ ).

Serum ferritin values were lower with progressing gestation, from $27 \%$ lower during weeks $16-20(\operatorname{expB}=0.73)$ up to $59 \%$ lower above 29 weeks of gestation $(\operatorname{expB}=0 \cdot 41)$ compared with those who were recruited before 16 weeks of gestation ( $P$ for linear trend $<0.001$ ) (Table 3). Serum CRP and ACT were independently associated with higher serum ferritin values, although the associations were attenuated when both acute-phase reactants were included in the model. We compared the models with both acute-phase reactants as explanatory variables with the models excluding either of them using likelihood ratio tests, and concluded that both acute-phase reactants should be included (data not shown). We could not reveal any relationship between serum ferritin and parity.

In accordance with the reduction in serum ferritin levels, serum sTfR levels increased with the advancing stage of pregnancy (Table 3). There was a small, but significant decrease in serum sTfR levels, with age in the simple regression analysis indicating better Fe status with increasing age. Parity was also associated with lower sTfR levels in simple regression analysis. However, when both age and parity were included in the multiple linear regression model, none of them was significant predictors of serum sTfR. There was no interaction

Table 2. Associations between the acute-phase proteins C-reactive protein (CRP) and $\alpha_{1}$-antichymotrypsin (ACT) among 738 pregnant women

(Back-transformed exponentiated terms (expB) and 95\% confidence intervals)

\begin{tabular}{|c|c|c|c|c|c|}
\hline & \multirow[b]{2}{*}{$n$} & \multicolumn{2}{|c|}{ CRP (mg/l) } & \multicolumn{2}{|c|}{ ACT $(g / l)$} \\
\hline & & $\operatorname{expB}$ & $95 \% \mathrm{Cl}$ & $\operatorname{expB}$ & $95 \% \mathrm{Cl}$ \\
\hline \multicolumn{6}{|c|}{$\begin{array}{l}\text { Gestational } \\
\text { age (weeks) }\end{array}$} \\
\hline $7 \cdot 0-16 \cdot 0$ & 149 & 1 & - & 1 & - \\
\hline $16 \cdot 1-20 \cdot 3$ & 143 & 1.06 & $0.88,1.28$ & 1.00 & $0.99,1.02$ \\
\hline $20 \cdot 4-24.0$ & 145 & $1.29^{*}$ & $1.04,1.59$ & 1.02 & $1.00,1.04$ \\
\hline $24 \cdot 1-28 \cdot 6$ & 142 & $1.29^{*}$ & $1.05,1.60$ & 1.01 & $0.99,1.03$ \\
\hline$\geq 28.7$ & 141 & 1.19 & $0.97,1.47$ & 0.99 & $0.98,1.01$ \\
\hline
\end{tabular}

between age and parity ( $P$ for interaction $>0 \cdot 2)$. Although not to the same degree as serum ferritin, serum sTfR level was elevated by inflammation. However, the association between serum CRP and sTfR was not significant when ACT was included in the statistical model. Nonetheless, when one or both markers were elevated, sTfR underestimated, while serum ferritin overestimated Fe status during inflammation.

Including season, prior use of nutritional supplements and maternal height in the models did not change the estimates of other variables, and they were not included in the models presented in Table 3.

Adjusting the serum ferritin values for the two inflammatory markers $(4 \times 5$ potential combinations of different degrees of elevation of the acute-phase markers) increased the proportion of serum ferritin $<12 \mu \mathrm{g} / \mathrm{l}$ from 25 to $33 \%$ (Table 4 ). On the contrary, adjusting serum sTfR values decreased the proportion of serum sTfR $>2.3 \mathrm{mg} / 1$ from 52 to $47 \%$. A similar analysis with only four categories (CRP normal and ACT normal, CRP elevated, CRP and ACT elevated, ACT elevated) using cut-off values $>3 \mathrm{mg} / \mathrm{l}$ for CRP and $\geq 0.3 \mathrm{~g} / \mathrm{l}$ for ACT gave very similar adjusted median values and proportion of individuals classified as Fe deficient.

As expected, the $\mathrm{Hb}$ level of women measured after week 20 was reduced by $8-10 \mathrm{~g} / \mathrm{l}$ compared with those measured before week 7 (Table 5). Serum CRP was not significantly associated with $\mathrm{Hb}$. On the contrary, elevated serum ACT value above $0.5 \mathrm{~g} / 1$ was associated with about $10 \mathrm{~g} / 1$ lower $\mathrm{Hb}$. However, the strength of this association decreased when serum ferritin and sTfR were included in the model. Serum ferritin and STfR were independently associated with $\mathrm{Hb}$; depleted Fe stores defined as serum ferritin $<12 \mu \mathrm{g} / \mathrm{l}$ were associated with a suppression of $\mathrm{Hb}$ at $3.2 \mathrm{~g} / \mathrm{l}$, while an abnormally high concentration $(<150 \mu \mathrm{g} / \mathrm{l})$ was associated with a $6 \cdot 0 \mathrm{~g} / 1$ suppression of $\mathrm{Hb}$ compared with women with serum ferritin levels in the normal range. When serum ACT and serum CRP were not included in the model, the high serum ferritin values were associated with an even larger deficit of $\mathrm{Hb}(-10 \cdot 0(-15 \cdot 1,-4 \cdot 8) \mathrm{g} / \mathrm{l}$; data not shown $)$. In line with the cut-off values suggested to define serum sTfR indicating erythropoiesis $(1.9<\mathrm{sTfR} \leq 2.3 \mathrm{mg} / \mathrm{l})$ and Fe-deficiency anaemia (sTfR $>2.3 \mathrm{mg} / \mathrm{l}$ ), we only found a significantly lower $\mathrm{Hb}$ in women with $\mathrm{sTfR}>2.3 \mathrm{mg} / \mathrm{l}$ in this group of pregnant women.

\section{Discussion}

In the present large cross-sectional study, we found that more than half of the pregnant women were anaemic, while onethird had Fe deficiency based on the adjusted serum ferritin values. These results are in line with the general assumption that $\mathrm{Fe}$ deficiency is one of the main causes of anaemia, accounting for about half of anaemia cases, depending on other underlying factors such as malaria ${ }^{(21)}$.

We observed continuously poorer Fe status with advancing stage of pregnancy indicated by lower ferritin and higher sTfR concentrations. At the same time, Hb was lowest between 24 and 28 weeks of gestation. The progressive Fe depletion throughout pregnancy is in agreement with previous 
Table 3. Estimated effects on serum ferritin and soluble transferrin receptors (sTfR) among 738 pregnant women from simple and multiple regression analyses

(Back-transformed exponentiated terms (expB) and $95 \%$ confidence intervals) $\dagger$

\begin{tabular}{|c|c|c|c|c|c|c|c|c|c|}
\hline \multirow[b]{3}{*}{ Variables } & \multirow[b]{3}{*}{$n \ddagger$} & \multicolumn{4}{|c|}{ Serum ferritin } & \multicolumn{4}{|c|}{ sTfR } \\
\hline & & \multicolumn{2}{|c|}{ Simple regression } & \multicolumn{2}{|c|}{ Multiple regression } & \multicolumn{2}{|c|}{ Simple regression } & \multicolumn{2}{|c|}{ Multiple regression } \\
\hline & & $\operatorname{expB}$ & $95 \% \mathrm{Cl}$ & $\operatorname{expB}$ & $95 \% \mathrm{Cl}$ & $\operatorname{expB}$ & $95 \% \mathrm{Cl}$ & $\operatorname{expB}$ & $95 \% \mathrm{Cl}$ \\
\hline \multicolumn{10}{|c|}{ Gestational age (weeks) } \\
\hline $7 \cdot 0-16 \cdot 0$ & 149 & 1 & & 1 & & 1 & & 1 & \\
\hline $16 \cdot 1-20 \cdot 3$ & 143 & $0 \cdot 75^{\star \star}$ & $0.59,0.94$ & $0.73^{\star \star \star}$ & $0.59,0.89$ & 1.08 & $1 \cdot 00,1 \cdot 16$ & $1.08^{\star}$ & $1 \cdot 00,1 \cdot 17$ \\
\hline $20 \cdot 4-24.0$ & 146 & $0.60^{\star \star \star}$ & $0.48,0.76$ & $0.54^{\star \star \star}$ & $0.44,0.66$ & $1 \cdot 17^{\star \star \star}$ & $1.09,1.27$ & $1 \cdot 17^{\star \star *}$ & $1.08,1.26$ \\
\hline $24 \cdot 1-28 \cdot 6$ & 142 & $0.57^{\star \star \star}$ & $0.45,0.71$ & $0.50^{\star \star *}$ & $0.39,0.59$ & $1 \cdot 29^{\star \star \star}$ & $1.19,1.39$ & $1 \cdot 28^{\star \star \star}$ & $1.19,1.39$ \\
\hline$\geq 28.7$ & 141 & $0.43^{\star \star \star}$ & $0.34,0.54$ & $0.41^{\star \star *}$ & $0.32,0.49$ & $1.35^{\star \star \star}$ & $1.25,1.46$ & $1.36^{\star * *}$ & $1.26,1.46$ \\
\hline Age (years) & 732 & 1.00 & $0.98,1.01$ & 1.01 & $1.00,1.03$ & $0.99^{\star \star \star}$ & $0.99,1.00$ & 1.00 & $0.99,1.00$ \\
\hline \multicolumn{10}{|l|}{ Parity§ } \\
\hline Primi & 179 & 1 & & 1 & & 1 & & 1 & \\
\hline Secundi & 118 & 1.01 & $0.79,1.27$ & 1.00 & $0.82,1.23$ & 0.94 & $0.87,1.01$ & 0.98 & $0.90,1.06$ \\
\hline Tertio & 86 & 0.86 & $0.66,1.12$ & 0.90 & $0.71,1.15$ & 0.95 & $0.87,1.03$ & 0.98 & $0.90,1.07$ \\
\hline Multi & 191 & 0.90 & $0.74,1.11$ & 0.90 & $0.70,1.16$ & $0.87^{\star \star \star}$ & $0.82,0.93$ & 0.93 & $0.84,1.02$ \\
\hline Malaria parasitaemia & 416 & 1.09 & $0.94,1.27$ & 1.01 & $0.89,1.15$ & 1.01 & $0.95,1.06$ & 0.98 & $0.93,1.03$ \\
\hline \multicolumn{10}{|c|}{ C-reactive protein $(\mathrm{mg} / \mathrm{l})$} \\
\hline$\leq 3$ & 355 & 1 & & 1 & & 1 & & 1 & \\
\hline$>3-10$ & 214 & $1.23^{*}$ & $1.04,1.44$ & $1 \cdot 17^{\star}$ & $1.00,1.36$ & $1.08^{*}$ & $1.01,1.14$ & 1.05 & $0.99,1.12$ \\
\hline$>10-20$ & 71 & $1 \cdot 74^{\star \star \star}$ & $1.37,2.22$ & 1.23 & $0.96,1.57$ & $1 \cdot 13^{* *}$ & $1.04,1.24$ & 1.06 & $0.97,1.16$ \\
\hline \multirow{2}{*}{\multicolumn{10}{|c|}{$\alpha_{1}-$ Antichymotrypsin $(\mathrm{g} / \mathrm{l})$}} \\
\hline & & & & & & & & & \\
\hline$<0.3$ & 247 & 1 & & 1 & & 1 & & 1 & \\
\hline $0.3-<0.4$ & 344 & $1 \cdot 16^{*}$ & $1.00,1.35$ & 1.02 & $0.88,1.19$ & 1.03 & $0.97,1.09$ & 1.04 & $0.98,1.11$ \\
\hline $0.4-<0.5$ & 89 & $2 \cdot 61^{\star \star *}$ & $2 \cdot 09,3 \cdot 26$ & $1.95^{\star * *}$ & $1.52,2.51$ & $1 \cdot 18^{* \star *}$ & $1.09,1.29$ & $1 \cdot 14^{\star \star}$ & $1.03,1.26$ \\
\hline $0.5-<0.6$ & 26 & $4 \cdot 14^{\star \star \star}$ & $2 \cdot 86,5.98$ & $2 \cdot 83^{\star \star \star}$ & $1.88,4.31$ & $1 \cdot 21^{*}$ & $1.05,1.39$ & $1 \cdot 20^{*}$ & $1.02,1.40$ \\
\hline$\geq 0.6$ & 27 & $7 \cdot 69^{\star \star \star}$ & $5 \cdot 36,11 \cdot 1$ & $5.05^{\star \star \star}$ & $3 \cdot 29,7 \cdot 77$ & $1 \cdot 10$ & $0.96,1.27$ & 1.02 & $0.87,1.21$ \\
\hline
\end{tabular}

Values were significantly different from the reference category within a given variable: ${ }^{\star} P<0.05,{ }^{\star \star} P<0.01,{ }^{\star \star \star} P<0.001$

† Multiple imputations were applied to the variable parity.

$¥$ The numbers correspond to the simple linear regression models.

$\S$ Information available only for 574 women. $n$ refers to the available data, not to the imputed data.

observations from low-income ${ }^{(22)}$ as well as high-income settings ${ }^{(23-25)}$. This could lead to maternal nutritional depletion with increasing number of pregnancies as reported previously ${ }^{(25-27)}$. However, this is not supported by our data where parity was not associated with any of the Fe status markers. We have previously observed the same tendency for vitamin A status, which was also not affected by parity ${ }^{(14)}$. We also published similar findings among HIV-positive pregnant Zimbabwean women ${ }^{(22)}$. However, our data cannot sufficiently address maternal nutritional depletion in high-risk groups such as women with a short interpregnancy interval or very young women as emphasised previously ${ }^{(27)}$. Likewise, the crosssectional design of the present study prevents conclusions on nutritional depletion in individuals. Whether the absence of an obvious depletion is explained by biological mechanisms securing repletion of nutrient stores, or by socio-cultural mechanisms by which priority is given to mothers or lactating women remains unexplained.

While serum ACT was not influenced by stage of pregnancy, serum CRP was elevated by $29 \%$ from 20 to 28 weeks of gestation, but not significantly elevated in later pregnancy in contrast to what has been reported previously ${ }^{(28,29)}$. Both serum ACT and serum CRP levels were lower among women of higher parity, suggesting that the acute-phase reaction in response to pregnancy was more pronounced during the first pregnancies. We have previously

Table 4. Unadjusted values of serum ferritin (SF) and serum soluble transferrin receptors (sTfR) and values adjusted for inflammation using two different approaches

(Medians and interquartile ranges $(\mathrm{IQR}))^{\star}$

\begin{tabular}{|c|c|c|c|c|c|c|c|c|}
\hline \multirow[b]{2}{*}{ Adjustment method } & \multicolumn{4}{|c|}{ SF $(\mu \mathrm{g} / \mathrm{l})$} & \multicolumn{4}{|c|}{$\mathrm{sTfR}(\mathrm{mg} / \mathrm{l})$} \\
\hline & Median & IQR & $n<12$ & $\%$ & Median & IQR & $n>2.3$ & $\%$ \\
\hline Unadjusted & 23.4 & $11 \cdot 9-49.0$ & 184 & $25 \cdot 1$ & 2.35 & $1.95-3.06$ & 381 & 52 \\
\hline Multiple categories $\dagger$ & $17 \cdot 3$ & $9 \cdot 4-31 \cdot 3$ & 246 & 33.3 & $2 \cdot 22$ & $1 \cdot 83-2 \cdot 86$ & 344 & 46 \\
\hline Four categoriesł & $16 \cdot 6$ & $8 \cdot 6-33 \cdot 2$ & 276 & 37.4 & $2 \cdot 18$ & $1 \cdot 80-2 \cdot 81$ & 326 & 44.4 \\
\hline
\end{tabular}

* All adjustments were based on linear regression models using $\log _{\mathrm{e}}$-transformed outcome variables.

† Multiple combinations of four degrees of elevation of C-reactive protein (CRP) and five degrees of elevation of $\alpha_{1}$-antichymotrypsin (ACT).

‡Four inflammation groups: CRP and ACT normal; only CRP elevated; CRP and ACT elevated; only ACT elevated. CRP levels $>3 \mathrm{mg} / \mathrm{l}$ and ACT levels $\geq 0.3 \mathrm{~g} / \mathrm{l}$ were used as the cut-off values. 
Table 5. Estimated effects on $\mathrm{Hb}(\mathrm{g} / \mathrm{l})$ among 738 pregnant women from multiple linear regression analysis.

(Regression coefficients (B) and $95 \%$ confidence intervals) $\dagger$

\begin{tabular}{|c|c|c|c|c|c|}
\hline & \multirow[b]{2}{*}{$n \S$} & \multicolumn{2}{|c|}{ Model $1 \ddagger$} & \multicolumn{2}{|c|}{ Model $2 \ddagger$} \\
\hline & & $\mathrm{B}$ & $95 \% \mathrm{Cl}$ & B & $95 \% \mathrm{Cl}$ \\
\hline \multicolumn{6}{|c|}{ Gestational age (weeks) } \\
\hline $7 \cdot 0-16 \cdot 0$ & 133 & 0 & & 0 & \\
\hline $16 \cdot 1-20 \cdot 3$ & 137 & $-3.83^{\star}$ & $-7.27,-0.38$ & -2.69 & $-6.06,0.68$ \\
\hline $20 \cdot 4-24.0$ & 141 & $-8.54^{\star \star \star}$ & $-12 \cdot 0,-5 \cdot 08$ & $-7 \cdot 35^{\star \star \star}$ & $-10.8,-3.91$ \\
\hline $24 \cdot 1-28 \cdot 6$ & 133 & $-10 \cdot 6^{\star \star \star}$ & $-14 \cdot 1,-7 \cdot 10$ & $-8 \cdot 26^{\star \star \star}$ & $-11 \cdot 8,-4.76$ \\
\hline$\geq 28 \cdot 7$ & 139 & $-8 \cdot 44^{\star \star \star}$ & $-11.9,-4.95$ & $-5 \cdot 46^{\star \star}$ & $-9.05,-1.88$ \\
\hline Age (years) & 694 & 0.12 & $-0.20,0.44$ & 0.09 & $-0.22,0.40$ \\
\hline \multicolumn{6}{|l|}{ Parity\| } \\
\hline Primi & 174 & 0 & & 0 & \\
\hline Secundi & 108 & -0.21 & $-3.92,3.50$ & -0.08 & $-3.71,3.54$ \\
\hline Tertio & 81 & 0.73 & $-3.63,5.08$ & 0.78 & $-3.46,5.03$ \\
\hline Multi & 180 & 1.97 & $-2.54,6.49$ & 1.91 & $-2 \cdot 48,6 \cdot 30$ \\
\hline Malaria paras & & $2 \cdot 18$ & $0.04,4.39$ & $2 \cdot 19^{\star}$ & $0.05,4.33$ \\
\hline \multicolumn{6}{|c|}{ C-reactive protein (mg/l) } \\
\hline$<3$ & 334 & 0 & & 0 & \\
\hline $3-10$ & 198 & -0.76 & $-3.41,1.89$ & -0.68 & $-3.26,1.90$ \\
\hline $10-20$ & 69 & $-1 \cdot 13$ & $-5 \cdot 24,2 \cdot 98$ & $-1 \cdot 16$ & $-5 \cdot 19,2 \cdot 88$ \\
\hline$>20$ & 90 & -4.24 & $-8.96,0.49$ & $-4 \cdot 38$ & $-8.98,0.23$ \\
\hline \multicolumn{6}{|c|}{$\alpha_{1}$-Antichymotrypsin $(\mathrm{g} / \mathrm{l})$} \\
\hline$<0.3$ & 232 & 0 & & 0 & \\
\hline $0.3-<0.4$ & 326 & 0.22 & $-2 \cdot 35,2 \cdot 80$ & 0.45 & $-2.04,2.95$ \\
\hline $0.4-<0.5$ & 84 & -2.59 & $-6.99,1.81$ & -1.67 & $-5 \cdot 96,2.62$ \\
\hline $0.5-<0.6$ & 23 & $-11 \cdot 4^{\star \star}$ & $-18 \cdot 6,-4.29$ & $-9 \cdot 82^{\star \star}$ & $-16 \cdot 8,-2 \cdot 82$ \\
\hline$\geq 0.6$ & 26 & $-8 \cdot 72^{\star}$ & $-16 \cdot 1,-1 \cdot 38$ & $-6 \cdot 92^{\star}$ & $-14 \cdot 3,0.46$ \\
\hline \multicolumn{6}{|c|}{ Serum ferritin $(\mu \mathrm{g} / \mathrm{l})$} \\
\hline$<12$ & 175 & - & - & $-3 \cdot 27^{\star}$ & $-5.95,-0.59$ \\
\hline $12-150$ & 484 & - & - & 0 & \\
\hline$>150$ & 33 & - & - & $-6.03^{\star}$ & $-11.4,-0.66$ \\
\hline \multicolumn{6}{|c|}{ Serum sTfR (mg/l) } \\
\hline$<1.9$ & 153 & - & - & 0 & \\
\hline $1 \cdot 9-2 \cdot 3$ & 175 & - & - & $2 \cdot 16$ & $-0.95,5.27$ \\
\hline$>2 \cdot 3$ & 362 & - & - & $-5 \cdot 25^{\star \star \star}$ & $-8.10,-2.39$ \\
\hline
\end{tabular}

Values were significantly different between the reference categories within a given variable: ${ }^{\star} P<0.05,{ }^{\star *} P<0.01,{ }^{\star \star *} P<0.001$.

† Multiple imputations were applied to the variable parity.

¥Both models were multiple linear regression models, and were further adjusted for season and prior use of nutritional supplements

in current pregnancy. Model 2 included the markers of iron status.

$\S$ The numbers correspond to the full model; $\mathrm{Hb}$ was only available for 694 women.

$\| n$ refers to the available data, not to the imputed data.

reported higher serum ACT during the first pregnancy ${ }^{(30)}$ as well as after the first delivery in lactating women ${ }^{(31)}$. We did not collect any clinical information, and are therefore not able to distinguish between infection-induced and a possible pregnancy-induced inflammation.

The Orion Diagnostica test kit that was used to measure serum sTfR levels in the present study was obviously calibrated against another standard than the more widely used kit from RAMCO laboratories, leading to different cut-off values and little comparability between studies. The discrepancy between normal values prevented the use of established cut-off values for sTfR in the present study. While this is an important limitation for comparison with other studies, it should not affect the internal validity of the findings. The problem with the lack of standardisation has already been acknowledged, and the need to standardise sTfR assays was emphasised in a recent WHO report ${ }^{(32)}$.

The high proportion of women with sTfR levels $>2.3 \mathrm{mg} / \mathrm{l}$ even in individuals who had normal serum ferritin first of all highlights that cut-off values for Fe status markers may not be appropriate in pregnancy and during inflammation.
While Fe deficiency may be underestimated based on serum ferritin in the presence of inflammation, Fe deficiency based on STfR may be overestimated in pregnancy because erythropoiesis is part of the normal physiology. The high proportion of elevated sTfR irrespective of Fe stores probably reflects a combination of tissue Fe deficiency and pregnancy-related erythropoiesis. In a prospective study from Sweden, Fe-replete individuals also had elevated sTfR levels with progressing pregnancy ${ }^{(24)}$, and their sTfR levels did not return to pre-pregnant values postpartum. On the contrary, sTfR levels at 3 months postpartum were comparable with nonpregnant values in a cross-sectional study from Korea ${ }^{(33)}$. These conflicting results underline that we know little about how the commonly used Fe status indicators react to the normal physiology during pregnancy, and whether maternal adaptation mechanisms are sufficient to regain pre-pregnancy Fe stores after delivery. It is important that physiologically normal changes in pregnancy can be differentiated from nutritional depletion. As long as there is no 'gold' standard for Fe status in pregnant women, we need prospective data comparing Fe status markers before, during and after pregnancy in 
order to define suitable cut-off values for Fe deficiency in pregnancy. In line with previous recommendations ${ }^{(29,34)}$, our data emphasise the need to define and apply pregnancyspecific cut-off values for sTfR in order to improve its value as an indicator of Fe status.

Serum ferritin and sTfR were both affected by the acutephase response, although the effect was less pronounced for serum sTfR. There is consensus that markers of Fe status, especially serum ferritin and particularly in populations with a high burden of infectious diseases, should not be used without adjusting for the acute-phase response $\mathrm{e}^{(7,8,12,35,36)}$. Recently, it was emphasised that obesity-related inflammation defined as CRP levels $>2 \mathrm{mg} / \mathrm{l}$ also led to increased serum ferritin values ${ }^{(37)}$. As mentioned, the acute-phase reaction is complex and affects, either positively or negatively, the expression of many different proteins ${ }^{(11)}$. The acute-phase reaction is not stereotypic, but depends on inflammatory conditions ${ }^{(11)}$. It is widely accepted that serum ferritin is increased when serum CRP is elevated, but it is also recognised that serum ferritin returns to normal values later than serum $\mathrm{CRP}^{(7,8,18)}$, adding the need for a different acute-phase protein. The ideal solution would be to identify an acute-phase protein that follows the same inflammatory response as ferritin, with any cause of inflammation. However, such agent has not yet been identified. We used serum ACT to account for the late effects of the acute-phase reaction, as suggested by Calvin et al. ${ }^{(18)}$, although $\alpha_{1}$-acid glycoprotein is becoming the most commonly used acute-phase protein in addition to CRP.

Based on data from thirty studies from different settings, Thurnham et al. ${ }^{(8)}$ estimated a set of correction factors for the adjustment of serum ferritin for various combinations of elevated CRP and $\alpha_{1}$-acid glycoprotein. A simplistic approach was applied with only one cut-off point for each acute-phase protein. While we strongly support the definition of a simple approach, our data suggest the necessity of using more categories for each acute-phase protein based on their actual association with serum ferritin. However, applying the simpler approach using the four categories (none, CRP, CRP + ACT or ACT alone being elevated) and only one cut-off for each acute-phase protein produced similar adjusted values to those from the more complex adjustment with $4 \times 5$ categories. While Thurnham used values $>5 \mathrm{mg} / 1$ to define elevated CRP, we used a lower cut-off of $3 \mathrm{mg} / \mathrm{l}$. We also used ACT instead of $\alpha_{1}$-acid glycoprotein, and suggest that cut-off values should be carefully reconsidered and reflect the lowest values at which ferritin and STfR are increased. We believe that the risk of overcorrecting is small, since it is unlikely that individuals affected by inflammation have truly larger Fe stores than healthy individuals. With recent development of high-sensitivity methods for CRP, it might become evident that $\mathrm{Fe}$ status markers are affected at an even lower grade of inflammation. However, the assay for ACT was more sensitive, and the relationship was not linear below a certain level. By inspection of LOWESS (locally weighted scatterplot smoothing) plots of $\log$ ferritin and ACT, the relationship appeared linear only above approximately $0.3 \mathrm{~g} / \mathrm{l}$.

Serum ferritin and serum sTfR independently predicted $\mathrm{Hb}$ in a model adjusted for stage of pregnancy and inflammation.
As expected, poor Fe status predicted lower Hb values. However, we also observed a strong negative association between elevated serum ferritin $(>150 \mu \mathrm{g} / \mathrm{l})$ and $\mathrm{Hb}$, even after adjusting for serum CRP and serum ACT. This suggests that we have not fully adjusted for the acute-phase reaction. While current malaria parasitaemia was included, further adjustment for the acute-phase reaction could have been applied by adding variables such as HIV status or other acute and chronic infections. While HIV prevalence was low in the study area ${ }^{(16)}$, it may have contributed to the association between high serum ferritin and lower $\mathrm{Hb}$ as well.

The main strength of the present cross-sectional study was its large size and the wide distribution of the participants in terms of stage of pregnancy and acute-phase response. However, the cross-sectional design makes us unable to exclude reverse causality. Data on micronutrient status of pregnant women in low-income settings are limited and most studies are small. Our estimates of Fe status during pregnancy are of course context-specific, and may not be generalised to other populations where dietary intake as well as type and frequency of infections differ. However, the biological associations between Fe status and inflammation and gestation are probably not different from other populations. We did not collect sufficient data on malaria and other infections to address the infections associated with the inflammation in the analyses.

In conclusion, longitudinal data of Fe status before, during and after pregnancy as well as before, during and after inflammation are needed to further understand the dynamics of Fe status during pregnancy and inflammation. We suggest that the cut-off values used to define Fe deficiency in nonpregnant individuals are not directly applicable in pregnant women and should be revised. Furthermore, we suggest refining the approach to adjust serum ferritin and serum sTfR values for the confounding effect by the acute-phase response.

\section{Acknowledgements}

The present study was funded by the Royal Veterinary and Agricultural University, Denmark, the Denmark's International Development Agency (DANIDA), the Novo Nordisk Foundation, UNICEF, the Foundation of 1870, and Jakob \& Olga Madsen's Foundation. P. A. holds a research professorship grant from the Novo Nordisk Foundation.

The authors' contributions are as follows: P. K., P. A. and H. F. designed the research; P. K. supervised the data collection and laboratory analyses, performed the statistical analysis, and prepared the first draft of the manuscript; C. R. supervised the statistical analyses; H. F. and P. A. participated in the study design and supervised the fieldwork. All authors read and approved the final manuscript.

There are no conflicts of interest.

\section{References}

1. Allen LH (2000) Anemia and iron deficiency: effects on pregnancy outcome. Am J Clin Nutr 71, 1280S-1284S. 
2. Black RE, Allen LH, Bhutta ZA, et al. (2008) Maternal and child undernutrition: global and regional exposures and health consequences. Lancet 371, 243-260.

3. Berger J, Wieringa FT, Lacroux A, et al. (2011) Strategies to prevent iron deficiency and improve reproductive health. Nutr Rev 69, Suppl. 1, S78-S86.

4. Pena-Rosas JP \& Viteri FE (2006) Effects of routine oral iron supplementation with or without folic acid for women during pregnancy. The Cochrane Database of Systematic Reviews, issue 3, CD004736 3

5. Haider BA, Olofin I, Wang M, et al. (2013) Anaemia, prenatal iron use, and risk of adverse pregnancy outcomes: systematic review and meta-analysis. BMJ 346, f3443.

6. Sazawal S, Black RE, Ramsan M, et al. (2006) Effects of routine prophylactic supplementation with iron and folic acid on admission to hospital and mortality in preschool children in a high malaria transmission setting: community-based, randomised, placebo-controlled trial. Lancet 367, 133-143.

7. Northrop-Clewes CA (2008) Interpreting indicators of iron status during an acute phase response - lessons from malaria and human immunodeficiency virus. Ann Clin Biochem 45, 18-32.

8. Thurnham DI, McCabe LD, Haldar S, et al. (2010) Adjusting plasma ferritin concentrations to remove the effects of subclinical inflammation in the assessment of iron deficiency: a meta-analysis. Am J Clin Nutr 92, 546-555.

9. Grant FK, Suchdev PS, Flores-Ayala R, et al. (2012) Correcting for inflammation changes estimates of iron deficiency among rural Kenyan preschool children. $J$ Nutr 142, 105-111.

10. Coad J \& Conlon C (2011) Iron deficiency in women: assessment, causes and consequences. Curr Opin Clin Nutr Metab Care 14, 625-634.

11. Gabay C \& Kushner I (1999) Acute-phase proteins and other systemic responses to inflammation. $N$ Engl J Med 340, 448-454.

12. Thurnham DI (2013) Interactions between nutrition and immune function: using inflammation biomarkers to interpret micronutrient status. Proc Nutr Soc 73, 1-8.

13. Raiten DJ, Ashour FAS, Ross AC, et al. (2015) Inflammation and Nutritional Science for Programs/Policies and Interpretation of Research Evidence (INSPIRE). J Nutr $\mathbf{1 4 5}$, 1039S-1108S

14. Kæstel P, Martinussen T, Aaby P, et al. (2012) Serum retinol is associated with stage of pregnancy and the acute phase response in pregnant women in Guinea-Bissau. J Nutr 142, 942-947.

15. Kæestel P, Michaelsen KF, Aaby P, et al. (2005) Effects of prenatal multimicronutrient supplements on birth weight and perinatal mortality: a randomised, controlled trial in Guinea-Bissau. Eur J Clin Nutr 59, 1081-1089.

16. Holmgren B, da Silva Z, Larsen O, et al. (2003) Dual infections with HIV-1, HIV-2 and HTLV-I are more common in older women than in men in Guinea-Bissau. AIDS 17, 241-253.

17. Cao C \& O'Brien KO (2013) Pregnancy and iron homeostasis: an update. Nutr Rev 71, 35-51.

18. Calvin J, Neale G, Fotherby KJ, et al. (1988) The relative merits of acute phase proteins in the recognition of inflammatory conditions. Ann Clin Biochem 25, 60-66.

19. Friis H, Gomo E, Kæstel P, et al. (2001) HIV and other predictors of serum $\beta$-carotene and retinol in pregnancy: a cross-sectional study in Zimbabwe. Am J Clin Nutr 73, $1058-1065$

20. Stoltzfus R \& Dreyfuss ML (1998) Guidelines for the Use of Iron Supplements to Prevent and Treat Iron Deficiency
Anemia. Washington DC: ILSI Press, International Life Science Institute.

21. Stevens GA, Finucane MM, De-Regil LM, et al. (2013) Global, regional, and national trends in haemoglobin concentration and prevalence of total and severe anaemia in children and pregnant and non-pregnant women for 1995-2011: a systematic analysis of population-representative data. Lancet Glob Health 1, e16-e25.

22. Friis H, Gomo E, Kæstel P, et al. (2001) HIV and other predictors of serum folate, serum ferritin, and hemoglobin in pregnancy: a cross-sectional study in Zimbabwe. Am J Clin Nutr 73, 1066-1073.

23. Walsh T, O'Broin SD, Cooley S, et al. (2011) Laboratory assessment of iron status in pregnancy. Clin Chem Lab Med 49, 1225-1230.

24. Akesson A, Bjellerup P, Berglund M, et al. (2002) Soluble transferrin receptor: longitudinal assessment from pregnancy to postlactation. Obstet Gynecol 99, 260-266.

25. Milman N (2006) Iron and pregnancy - a delicate balance. Ann Hematol 85, 559-565.

26. Milman N, Kirchhoff M \& Jorgensen T (1992) Iron status markers, serum ferritin and hemoglobin in 1359 Danish women in relation to menstruation, hormonal contraception, parity, and postmenopausal hormone treatment. Ann Hematol 65, 96-102.

27. King JC (2003) The risk of maternal nutritional depletion and poor outcomes increases in early or closely spaced pregnancies. J Nutr 133, 1732S-1736S.

28. Brewster JA, Orsi NM, Gopichandran N, et al. (2008) Gestational effects on host inflammatory response in normal and pre-eclamptic pregnancies. Eur J Obstet Gynecol Reprod Biol 140, 21-26.

29. Wheeler S (2008) Assessment and interpretation of micronutrient status during pregnancy. Proc Nutr Soc 67, 437-450.

30. Friis H, Gomo E, Kxestel P, et al. (2001) HIV and other predictors of serum $\beta$-carotene and retinol in pregnancy: a cross-sectional study in Zimbabwe. Am J Clin Nutr 73, $1058-1065$.

31. Friis H, Gomo E, Mashange W, et al. (2009) The acute phase response to parturition: a cross-sectional study in Zimbabwe. Afr J Reprod Health 13, 61-68.

32. Lynch S (2012) The rationale for selecting and standardizing iron status indicators. In World Health Organization Report Priorities in the Assessment of Vitamin A and Iron Status in Populations, 15-17 September 2010, Panama City, Panama. Geneva: World Health Organization.

33. Choi JW, Im MW \& Pai SH (2000) Serum transferrin receptor concentrations during normal pregnancy. Clin Chem $\mathbf{4 6}$ $725-727$.

34. Lynch S (2011) Improving the assessment of iron status. $A m J$ Clin Nutr 93, 1188-1189.

35. Lynch S (2011) Case studies: iron. Am J Clin Nutr 94 673S-678S

36. Engle-Stone R, Nankap M, Ndjebayi AO, et al. (2013) Plasma ferritin and soluble transferrin receptor concentrations and body iron stores identify similar risk factors for iron deficiency but result in different estimates of the national prevalence of iron deficiency and iron-deficiency anemia among women and children in Cameroon. $J$ Nutr $\mathbf{1 4 3}$, 369-377

37. Gartner A, Berger J, Bour A, et al. (2013) Assessment of iron deficiency in the context of the obesity epidemic: importance of correcting serum ferritin concentrations for inflammation. Am J Clin Nutr 98, $821-826$ 